\title{
Memory Strategy Training in Older Adults with Subjective Memory Complaints: A Randomized Controlled Trial
}

\author{
Nikita L. Frankenmolen, ${ }^{1,2}$ Eduard J. Overdorp, ${ }^{3}$ Luciano Fasotti, ${ }^{1,2}$ Jurgen A.H.R. Claassen, ${ }^{1,4}$ Roy P.C. Kessels, ${ }^{1,5}$ \\ AND Joukje M. Oosterman ${ }^{1}$ \\ ${ }^{1}$ Radboud University, Donders Institute for Brain, Cognition and Behaviour, Nijmegen, The Netherlands \\ ${ }^{2}$ Rehabilitation Centre Klimmendaal, Arnhem, The Netherlands \\ ${ }^{3}$ Gelre Medical Centre, Department of Medical Psychology, Zutphen, The Netherlands \\ ${ }^{4}$ Radboud University Medical Center, Department of Geriatric Medicine, Nijmegen, The Netherlands \\ ${ }^{5}$ Radboud University Medical Center, Department of Medical Psychology, Nijmegen, The Netherlands
}

(Received November 30, 2017; Final Revision June 21, 2018; Accepted June 22, 2018; First Published Online August 31, 2018)

\begin{abstract}
Objectives: Subjective memory complaints (SMC) in older adults are associated with a decline in everyday functioning and an increased risk for future cognitive decline. This study examines the effect of a memory strategy training compared to a control memory training on memory functioning in daily life. Methods: This was a randomized controlled trial with baseline, post-treatment, and 6-month follow-up assessments conducted in 60 older adults (50-87 years) with SMC. Participants were randomly assigned to either seven sessions of memory strategy training or seven sessions of control memory training. Both interventions were given in small groups and included psycho-education. Primary outcome measure was memory functioning in daily life. Objective measures of memory performance and self-reported measures of strategy use were included as secondary outcome measures. Results: Participants in each intervention group reported an improvement in personal memory goals $(p<.0005)$, up to 6 months after training. An interaction effect showed that participants following memory strategy training reported a larger improvement in personal memory goals $(p=.002)$. Both intervention groups improved on two memory tests $(p<.001$ and $p<.01)$. In the memory strategy training group, an increase in strategy use in daily life was the strongest predictor $(p<.05)$ of improvement in subjective memory functioning. Conclusions: Older adults with subjective memory complaints benefit from memory strategy training, especially in their memory functioning in daily life. (JINS, 2018, 24, 1110-1120)
\end{abstract}

Keywords: Cognitive training, Compensation strategies, Subjective cognitive impairment, Aging, Mild cognitive impairment, Activities of daily living

\section{INTRODUCTION}

Subjective memory complaints (SMC) in older adults are associated with a decline in everyday functioning and quality of life (Balash et al., 2013; Jessen et al., 2014; Montejo, Montenegro, Fernandez, \& Maestu, 2011). Although their cognitive functioning lies within the limits of normal cognitive aging, there is evidence that older adults with SMC may have an increased risk for future cognitive decline and dementia (Luck et al., 2015; Mendonça, Alves, \& Bugalho,

Correspondence and reprint requests to: Nikita L. Frankenmolen. Radboud University, Donders Institute for Brain, Cognition and Behaviour, Centre for Cognition, Montessorilaan 3, 6525 HR Nijmegen, The Netherlands. E-mail: n.frankenmolen@donders.ru.nl
2016; Mitchell, Beaumont, Ferguson, Yadegarfar, \& Stubbs, 2014), which stresses the need for early intervention.

Memory interventions can be divided into two approaches. The first approach is referred to as restorative training or brain training and is aimed at improving memory functioning. Studies on brain training or specifically working memory training have shown promising results on memory performance, but generalization to daily life functioning is limited (Owen et al., 2010; van Heugten, Ponds, \& Kessels, 2016). Since older adults with SMC still perform within the normal range on formal memory tests, yet experience complaints in daily life, memory training should be aimed at improving memory functioning in daily-life situations. Therefore, this study focusses on the second approach: compensatory training or strategy training, which is aimed at teaching people 
how to compensate for memory decline by using memory aids and other or additional cognitive functions.

A meta-analysis (Metternich Kosch, Kriston, Härter, \& Hüll, 2010) including 14 studies, compared various types of memory interventions in older adults with subjective memory complaints. These comparisons revealed that psychoeducation and cognitive restructuring and the combination of psychoeducation, cognitive restructuring, and memory strategy training are most effective for subjective memory functioning. A second meta-analysis (Gross et al., 2012), consisting of 33 memory intervention studies in healthy older adults, showed that the training of multiple strategies is most effective for improved performances on memory tests. However, the majority of studies performed so far lack methodological quality [e.g., no randomized controlled trial (RCT) or lacking an active control group] or focus exclusively on objective memory (test) performance. Thus, further research on generalization to daily life functioning is required (Gross et al., 2012; Metternich et al., 2010).

The present study examines the effect of a memory strategy training, including psychoeducation, cognitive restructuring and strategy training in older adults with SMC. To examine the efficacy of memory strategy training, an active control group was included that consisted of similar psychoeducation augmented with brain training (i.e., practicing memory tasks on a computer). The primary hypothesis is that for both intervention groups memory functioning in daily life should improve up to 6 months after training, with a larger improvement for memory strategy training. Furthermore, we expect similar effects for the secondary outcome measures, that is, performance on memory tests, strategy use in daily life, and quality of life. In addition, this study examines possible predictors for improvement following treatment.

\section{METHODS}

\section{Participants}

Sixty older adults (31 men) with SMC were included in the present study. All participants were aged between 50 and 87 years and lived independently in the community. Exclusion criteria were psychiatric disorders clinically diagnosed in accordance with the DSM-5 (e.g., depression, general anxiety disorder), neurological disorders affecting the brain, substance use disorder, and objective cognitive impairment. Fifty-four participants were recruited in collaboration with three outpatient memory clinics in the Netherlands, namely the Radboud University Medical Center and Canisius-Wilhelmina Hospital in Nijmegen, and Gelre Hospitals in Zutphen.

All patients within the memory clinic reported memory problems in their daily life functioning and actively sought help for their complaints. Patients were classified as having SMC by a multidisciplinary team of clinical specialists in each participating center. Cognitive impairment was excluded by either cognitive screening (e.g., Montreal Cognitive Assessment; Nasreddine et al., 2005) or a neuropsychological assessment using established normative data and clinical cutoff scores (i.e., $\geq 2 S D$ below the normative mean). In addition, the Instrumental Activities of Daily Living scale (IADL; Lawton \& Brody, 1969) was used as a measure of daily functioning.

None of the participants received a clinical diagnoses such as mild cognitive impairment (MCI) or dementia, and none of the participants had a psychiatric disorder in accordance with the DSM-5. In addition, six participants with SMC were recruited through advertisement. These participants were screened over the telephone for inclusion and exclusion criteria. They were asked whether they noticed everyday memory problems and whether they considered seeking help for their memory complaints. Furthermore, they were screened for the same exclusion criteria as the participants recruited from the memory clinics. The Telephone Interview Cognitive Status (TICS; Kempen, Meier, Bouwens, van Deursen, \& Verhey, 2007) was used to screen for cognitive deficits. Based on the inclusion and exclusion criteria, all participants fulfilled the current research criteria for subjective cognitive decline (Jessen et al., 2014), albeit that their complaints had to be predominantly in the memory domain for inclusion in our study.

Education level was rated according to the International Standard Classification of Education (ISCED) of the United Nations Educational, Scientific and Cultural Organisation Institute for Statistics (UNESCO-UIS). Based on previous research examining the effects of memory strategy training on subjective and objective memory functioning in adults with SMC (Metternich et al., 2010), a sample size of 30 participants in each group was required to detect a medium effect size with a power of 0.80 and alpha set at 0.05 . The estimated sample sizes are comparable with those of other studies evaluating the efficacy of memory strategy training (Lachman, Weaver, Bandura, Elliott, \& Lewkowicz, 1992; Scogin \& Prohaska, 1992).

\section{Procedure}

This study was approved by the Medical Review Ethics Committee region Arnhem-Nijmegen (CMO \#NL43519.091.013). The RCT is reported in accordance with the CONSORT guidelines (Altman et al., 2001). Participants gave written informed consent and all data was obtained in compliance with the Helsinki Declaration. Figure 1 displays the study procedure and the flow of participants throughout the trial. Randomization was performed per group of three to five participants using Random Allocation Software (RAS; http://randomallocatio.sourceforge. net/). Each group of participants was randomly allocated to either the memory strategy training or the control memory training. For each treatment arm a total of 8 groups consisting of - three to five participants were trained. The allocation was performed by the first author in the order of recruitment using randomly generated sequences. Assessments were performed by trained psychology students at baseline (T0), post-training (T1), and at a 6-month follow-up (T2). Both 
participants and students were blinded for treatment condition. Participants were told that two types of memory training were being compared, without further specification. The trainer was blinded for baseline assessment measures.

\section{Interventions}

The aim of this study was to examine the effect of memory strategy training compared to an active control condition. Therefore, other training variables were kept as equal as possible. Both interventions were given in groups of three to five participants, consisted of seven sessions (once a week) with a duration of 90 min per session and all participants were trained by the first author. In the first session all participants received psychoeducation on memory functioning and aging, and were able to share their experiences regarding memory complaints. Differences between subjective aging-related memory complaints and dementia were explained and participants were informed that their memory functioning (based on neuropsychological tests) was normal for their age. In addition, participants learned about the relation between stress, anxiety, and memory complaints. Subsequently, participants were asked to formulate three personal training goals in cooperation with the trainer. The psychoeducation and formulation of the personal goals were identical for both interventions. An overview of the training sessions is shown in Figure 1. Participants were instructed to attend all sessions, but they were allowed to miss one session.

\section{Memory strategy training}

An adapted version of the training protocol of KoningHaanstra, Berg, and Deelman (1990) was used. The original protocol was developed for patients with traumatic brain injury and consisted of 14 individual sessions of $60 \mathrm{~min}$. The sessions contained information about memory disorders after brain injury. Since older adults with SMC by definition have unimpaired levels of cognitive functioning, the protocol was shortened into seven group sessions of $90 \mathrm{~min}$ and the psychoeducational information was adjusted to the particular needs of older adults with SMC. During memory strategy training, memory strategies were explained, demonstrated and exercised in each session. Both external and internal memory strategies were addressed. External strategies consist of the use of memory aids, such as taking notes or using a calendar. Internal strategies include mnemonics, such as mental rehearsal or creating associations. Table 1 gives an overview of the strategies that were addressed per session.

Table 1. Description of the memory strategy training protocol per session

\begin{tabular}{|c|c|c|}
\hline Session & Summary & Content \\
\hline 1 & $\begin{array}{l}\text { Psychoeducation, cognitive-restructuring } \\
\text { Formulating memory goals }\end{array}$ & $\begin{array}{l}\text { Education about the memory system, normal aging-related memory decline and the } \\
\text { differences with types of dementia, the role of stress and healthy lifestyle, and how to } \\
\text { influence aging-related memory decline with the use of strategies. } \\
\text { Formulate three personal goals related to memory problems in daily life. }\end{array}$ \\
\hline 2 & External strategies & $\begin{array}{l}\text { Putting objects in a conspicuous and fixed place } \\
\text { Taking notes (preferably in a notebook) and making shopping lists } \\
\text { Use a diary to plan appointments } \\
\text { Set an alarm or timer } \\
\text { Use a calendar for birthdays or family appointments } \\
\text { Use the memory of someone else for important meetings }\end{array}$ \\
\hline 3 & Internal strategies part 1 & $\begin{array}{l}\text { Attention: deliberately concentrate on information that has to be remembered and try to } \\
\text { inhibit or prevent distraction. } \\
\text { Time: take some time to remember information and divide cognitive tasks throughout } \\
\text { the day. Try to prevent multi-tasking. } \\
\text { Repetition: actively rehearse information (out loud), preferably on several moments in } \\
\text { different situations. }\end{array}$ \\
\hline 4 & Internal strategies part 2 & $\begin{array}{l}\text { Associating: make associations between new information and old memories through } \\
\text { the use of mnemonics or visual imagery. } \\
\text { Structuring: categorize information, such as groceries and organize objects. } \\
\text { Looking forward and backward: use visual imagery to encode and plan future events or } \\
\text { to remember previous information, such as lost objects. }\end{array}$ \\
\hline 5 & $\begin{array}{l}\text { Rehearsal } \\
\text { Module "Remembering texts" }\end{array}$ & $\begin{array}{l}\text { Rehearsal of all external and internal strategies } \\
\text { Remember texts by using some external strategies (notes, marker) and all internal } \\
\text { strategies (attention, time, looking forward, associating, structuring, and repetition). }\end{array}$ \\
\hline 6 & $\begin{array}{l}\text { Module "Remembering conversations" } \\
\text { Module "Dealing with distraction" }\end{array}$ & $\begin{array}{l}\text { Remember conversations by using several internal strategies (looking forward, } \\
\text { attention, time, repetition, structuring, associating, and looking backward). } \\
\text { Deal with distraction by using both internal (attention, time, looking forward, and } \\
\text { backward) and external strategies (objects or notes). }\end{array}$ \\
\hline 7 & $\begin{array}{l}\text { Module "Remembering names and faces" } \\
\text { Evaluation }\end{array}$ & $\begin{array}{l}\text { Remember names and faces by using several internal strategies (attention, time, } \\
\text { repetition, and associating). }\end{array}$ \\
\hline
\end{tabular}


During the exercises, participants practiced the application of a strategy to daily life situations and their personal memory failures. For example, participants practiced to ask each other to repeat what he or she had said in a conversation, and they were stimulated to practice the skill of creating associations with the names of several people. Additionally, homework exercises were provided in which participants had to apply the learned strategies in daily life situations, related to their personal goals. At the end of each session, participants chose to work on at least one of their personal memory goals during the upcoming week.

For example, participants who wanted to learn to remember names of people were instructed to meet a new person, to repeat his/her name immediately after acquaintance, and to come up with associations linked to the name after talking to the person. An example of an assignment for an external strategy is that participants were instructed to buy a (family) calendar, to discuss the appointments and to-dos with their spouse at least weekly and to register these on the calendar.

\section{Control memory training}

For the active control memory training the computer program COGPACK® (http://markersoftware.com) was used. Participants practiced various attention and memory tasks. They were asked to memorize and reproduce various types of stimuli (e.g., names, landscapes, road directions). When possible, a theoretical link was made with the personal memory goals of the participants. For example, participants were explained that memorizing names could contribute to the ability to remember a name of a person you meet. In addition, in the spare time within each session and during session 7 , participants were instructed to repeat the exercises that were most relevant to their personal goals. The trainer did not actively stimulate the participants to use memory strategies during encoding.

\section{Outcome Measures}

\section{Primary outcome measures}

The primary outcome measure was memory functioning in daily life, which includes two self-report measures. First, we used personal goal ratings, an adapted version of the measure reported in Koning-Haanstra et al. (1990). The personal goal rating scale was developed to evaluate the progression on individual treatment goals. It is similar to Goal Attainment Scaling (GAS), which is widely used in rehabilitation settings (Turner-Stokes, 2009). However, whereas GAS is used to measure achievement of goals, personal goal ratings enable participants to evaluate how often they remember certain everyday events or facts, thereby making it a valuable measure to assess improvement in everyday memory functioning. For GAS, it is advised to formulate three to five key objectives that form priorities for the participant (Turner-Stokes, 2009). Due to the limited seven sessions of this memory strategy training, participants were asked to formulate three individual personal goals in terms of their most bothersome memory complaints. For example, "I want to remember the name of someone I meet" or "I want to remember where I left my keys or phone".

The personal goals were developed in the group at the end of the first session. The therapist provided some examples and helped the participants to formulate specific and realistic goals, related to the memory complaints that hindered them the most in daily life. Participants were encouraged to think about their possible goals at home and, if possible, consult their spouse. At the start of session 2, the personal goals were written down in a questionnaire format: the personal goal rating scale. Subsequently, participants were asked to rate each personal goal, indicating how often they currently remembered the item in their goal. For example, "How often do you remember the name of someone you meet?". Scores ranged from 1 (never) to 10 (always). For each participant, the average rating of the three goals was calculated.

In addition, subjective memory complaints were assessed using a 30-item memory complaint inventory, on which participants indicated the frequency of memory failures (Deelman \& Saan, 1990). Participants had to indicate how often they experience each memory failure using a 5-point rating scale ranging from 1 (never) to 5 (often). This inventory has a maximum score of 150 . A higher score indicates more memory complaints.

\section{Secondary outcome measures}

Memory functioning was assessed using the Rivermead Behavioural Memory Test - Third Edition as a measure of performance on everyday memory tasks (RBMT-3; Wilson et al., 2008). The RBMT-3 includes 14 subtests assessing aspects of visual, verbal, recall, recognition, immediate, delayed, and prospective everyday memory. Version 1 was used for assessments at $\mathrm{T} 0$ and $\mathrm{T} 2$ and alternate form version 2 was used at T1. The General Memory Index (GMI) was used as a measure for everyday memory, with a higher score indicating a better memory performance.

In addition, the Location Learning Test - Revised (LLT) was used as a measure of visuospatial memory (Bucks, Willison, Byrne, \& Kessels, 2011). Participants were asked to remember the location of 10 target items and place these items in the correct location within a $5 \times 5$ array. Version A was used at T0 and T2 and alternate version B was used at T1. The Total Displacement score on the five learning trials (i.e., the number of cells between the location chosen by the subject $v s$. the target location), the Learning Index (reflecting the slope of the learning curve, i.e., the improvement in performance across the individual trials), and the Delayed Recall score (i.e., the displacement score of the fifth learning trial minus the score on the delayed recall trial) were computed. For the Total Displacement score and the Delayed Recall scores, higher scores indicate a worse performance. For the Learning Index, a higher score reflects better learning.

Furthermore, the Rey Auditory Verbal Learning Test (RAVLT; Van der Elst, van Boxtel, van Breukelen, \& Jolles, 2005) was used as a measure for verbal memory. Participants 
were asked to remember and reproduce a wordlist consisting of 15 words. At T0, T1, and T2, three alternate forms were used (version A, B, and C). For the RAVLT, the total score on the five learning trials and the delayed recall score were computed, with higher scores indicating a better verbal memory performance.

Memory strategy use was assessed through the Strategy Use Inventory (SUI; Koning-Haanstra et al., 1990). The SUI includes a subscale for external strategy use and for internal strategy use. Participants had to indicate how often they use a certain strategy in daily life situations using a 5-point rating scale ranging from 1 (never) to 5 (often). The scores on each subscale were computed. The subscale external strategy use consists of six items, with a maximum score of 30 . The subscale internal strategy use consists of eight items, with a maximum score of 40 . A higher score indicates more frequent strategy use in daily life.

The RAND 36-item Short Form Health Survey (RAND-36; Brazier et al., 1992), was included as a self-report measure for quality of life. The survey is composed of 36 questions and standardized response choices across various domains of functioning (e.g., physical functioning, pain, mental health). A higher score indicates a higher quality of life.

\section{Other neuropsychological tests and questionnaires}

Several executive function tests were examined at baseline to obtain a cognitive profile of the participants. The "D-A-T" letter fluency test (Schmand, Groenink, \& Van den Dungen, 2008) was used to measure verbal fluency, the Trail Making Test; TMT (Lezak, Howieson, Bigler, \& Tranel, 2012) for cognitive flexibility and the Digit Span subtest from the Wechsler Adult Intelligence Scale - Fourth Edition (WAISIV; Wechsler, 2008) to measure working memory. IQ was estimated using the Dutch version of the National Adult Reading Test (NART; Nelson, 1982). The Geriatric Depression Scale - Short Form (GDS-15; Sheikh \& Yesavage, 1986) was used as a self-report measure of mood and the Instrumental Activities of Daily Living scale (IADL; Lawton \& Brody, 1969) as a self-report measure of daily functioning.

\section{Statistical Analyses}

For the statistical analyses IBM SPSS 21.0 was used. Demographic and baseline data of the two groups were compared using nonparametric, chi square, or Student's $t$ tests.

The main analysis consisted of a 2 (group; between-subjects) $\times 3$ (time; within-subjects) mixed (multivariate) analysis of variance for all outcome measures. Analyses were conducted on an intention-to-treat basis (Gupta, 2011). In case of missing outcomes, the last observation carried forward method was used. Furthermore, the proportion of patients who achieved a clinically significant improvement (i.e., an individual improvement of at least two standard deviations ( $S D \mathrm{~s}$ ) based on the baseline group's mean; Evans,
Margison, \& Barkham, 1998; Jacobson \& Truax, 1991) was computed for each group. This proportion was only calculated for participants who completed all three assessments. Bonferroni correction was used to correct for multiple comparisons. For the two primary outcome measures alpha was set at 0.025 . For the five secondary outcome measures alpha was set at 0.01 .

Additional exploratory analyses were conducted to examine the predictors for improvement following treatment. First, difference scores for $\mathrm{T} 2-\mathrm{T} 0$ and $\mathrm{T} 1-\mathrm{T} 0$ were calculated for the primary outcome measures (i.e., personal goal ratings and subjective memory complaints). Difference scores for T2-T0 and T1-T0 were also calculated for the subtest scores of internal and external strategy use in daily life. A priori correlation analyses were performed within each treatment group with age, IQ estimate, education level, the difference in internal and external strategy use (T1-T0 and T2-T0), and improvement following treatment, measured by the increase in personal goal ratings and decrease in subjective memory complaints. Subsequently, the variables that significantly correlated with the improvement following treatment measures were entered as predictors in a linear regression analysis. For the correlation analyses and the regression analyses, alpha was set at 0.05 .

\section{RESULTS}

Between October 2013 and April 2016, we approached 81 patients with an SMC diagnosis. All patients were eligible, but 27 patients declined to participate (schedule conflicts, or not interested in participating in a study). Additionally, 10 older adults with SMC were screened as result of the advertisement. Of these, 7 fulfilled the inclusion criteria, 1 of whom declined to participate. The remaining 60 participants were randomly assigned to the memory strategy training group $(N=31)$ or the control memory training group $(N=29)$. Three participants in each group withdrew from the study after baseline assessment or during treatment. Another three participants in each group did not complete the follow-up assessment. As one participant progressed to MCI, this participant was excluded at the follow-up assessment. Figure 1 shows the flow of the participants through the trial.

Table 2 shows the demographic characteristics and baseline results for both groups. A group difference was found in sex distribution $\left(\chi^{2}(1)=6.64 ; p=.019\right)$, with relatively more men in the memory strategy training group and more woman in the control memory training group. Sex was, however, unrelated to any of the outcome measures $(p>.05)$; therefore, it was not included in further analyses. Other demographic features (age, estimated IQ, and education level) did not differ between the two groups. Furthermore, no group differences were found on neuropsychological tests, personal goal ratings, or questionnaires at baseline. Results for the primary and secondary outcome measures at $\mathrm{T} 0, \mathrm{~T} 1$, and $\mathrm{T} 2$ are reported in Table 3. 


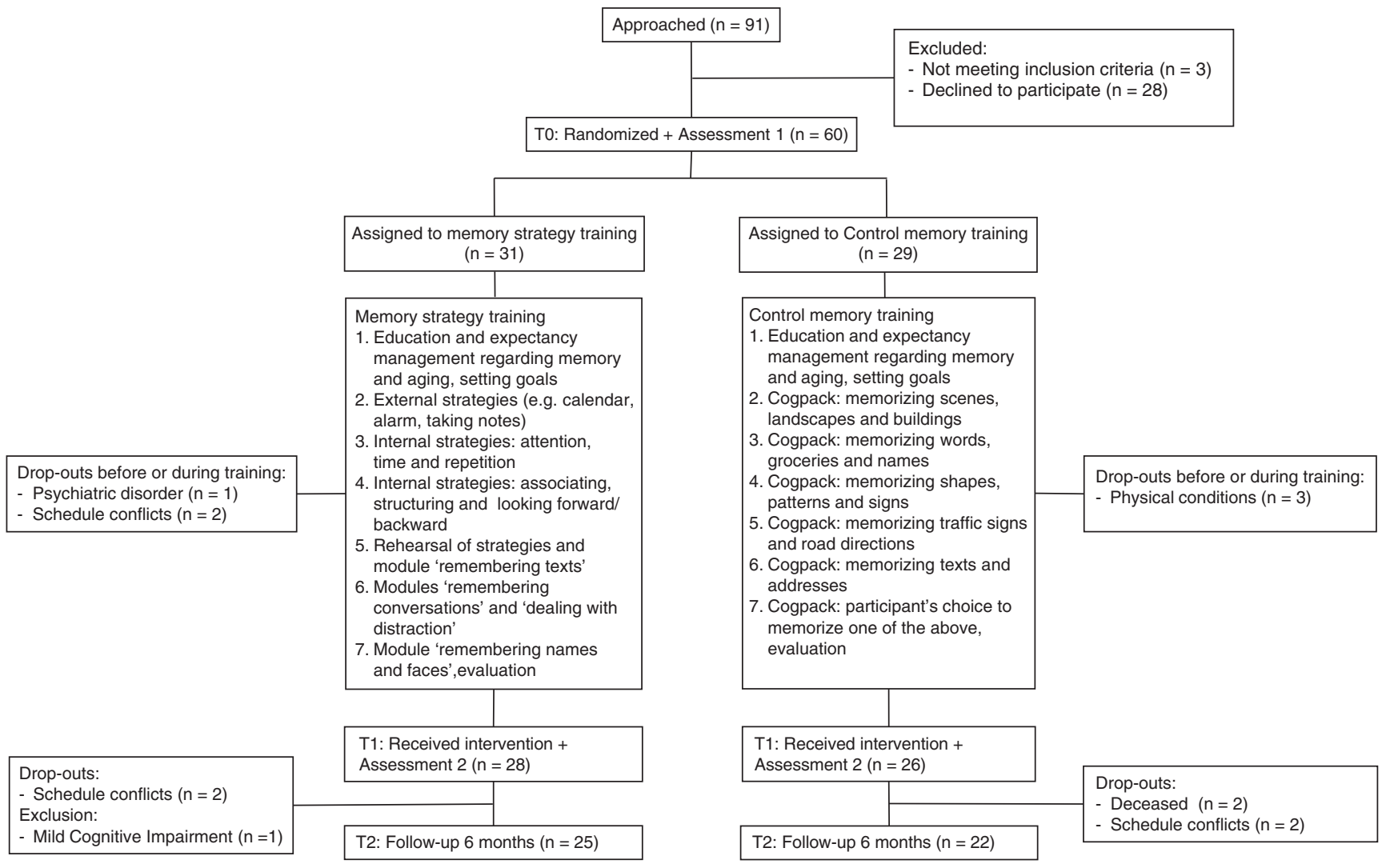

Fig. 1 . Flowchart of participants and overview of the training sessions for the memory training trial.

\section{Training Effects on Primary Outcome Measures}

\section{Personal goal ratings}

Figure 2 shows a significant time effect in both groups $(F$ $(2,53)=64.70 ; p<.0005)$ and a significant interaction effect $(F(2,53)=6.93 ; p=.002)$. Both groups improved on their personal goals, although the memory strategy training group showed a larger improvement compared to the control group. Overall, $76 \%$ of the participants who completed the memory strategy training and $23 \%$ of the participants who completed the control memory training achieved a clinically significant improvement at follow-up.

\section{Memory complaints}

No significant effects were found for the subjective memory complaints. The complaints did not significantly decrease following intervention $(F(2,57)=2.64 ; p=.080)$, and no significant interaction effect was found $(F(2,57)=1.81$; $p=.173)$. Moreover, only $4 \%$ of the participants in each group achieved a clinically significant improvement at follow-up (T2).

\section{Training Effects on Secondary Outcome Measures}

Results and statistical values are reported in Table 3. Both groups showed a significant improvement after training on two memory tests: the LLT and the RAVLT (both $p<.01$ ).
Moreover, a significant interaction effect was found on the learning index score of the LLT $(p=.002)$, in which the memory strategy training group showed an increase and the control group a decrease in the learning index score. No significant effects were found for the RBMT-3. Regarding strategy use, a significant time effect $(p<.001)$ was found in which there was an increase in internal strategy use in daily life. No significant effects were found for external strategy use. No significant main or interaction effects were found for quality of life.

\section{Predictors of Treatment Success}

The results of the correlation analyses are reported in Supplementary Table 1 . These analyses showed that the increase in internal strategy use (difference score T1-T0 and difference score T2-T0) and IQ estimate were significantly correlated with improvement in the memory strategy training group. Linear regression analyses with the difference in internal strategy use and IQ estimate as predictors showed that the increase in internal strategy use significantly predicted improvement in the memory strategy training group.

At $\mathrm{T} 1$, an increase in internal strategy use (T1-T0) was related to an increase in personal goal ratings $(\beta=.415$; $p=.035)$ and a decrease in subjective memory complaints $(\beta=-.447 ; p=.021)$. At $\mathrm{T} 2$, no significant predictors were found. Age, IQ estimate, education level, and external strategy use were not significantly associated with treatment 
Table 2. Baseline characteristics

\begin{tabular}{|c|c|c|c|c|c|c|c|c|}
\hline & \multicolumn{3}{|c|}{ Memory strategy training } & \multicolumn{3}{|c|}{ Control memory training } & \multirow[b]{2}{*}{$P$-Value } & \multirow[b]{2}{*}{ Cohen's $d$} \\
\hline & $M$ & $S D$ & $n$ & $M$ & $S D$ & $N$ & & \\
\hline Age & 66.2 & 7.3 & 31 & 68.0 & 7.8 & 29 & .34 & 0.24 \\
\hline Sex distribution & & & & & & & .02 & 0.71 \\
\hline Men $\%$ & $68 \%$ & 21 & $35 \%$ & 10 & & & & \\
\hline Women \% & $32 \%$ & 10 & $66 \%$ & 19 & & & & \\
\hline Education (ISCED) & 4.5 & 1.9 & 31 & 4.7 & 2.0 & 29 & .66 & 0.10 \\
\hline Estimated IQ & 106.1 & 17.6 & 29 & 109.2 & 17.3 & 29 & .50 & 0.18 \\
\hline \multicolumn{9}{|l|}{ Outcome measures } \\
\hline Memory Complaints Questionnaire & 75.8 & 14.1 & 31 & 79.9 & 14.0 & 29 & .26 & 0.29 \\
\hline Rating personal goals & 4.1 & 0.74 & 28 & 4.2 & 1.1 & 28 & .83 & 0.11 \\
\hline \multicolumn{9}{|l|}{ Strategy Use Inventory } \\
\hline External strategies & 21.9 & 4.6 & 31 & 22.4 & 3.1 & 29 & .66 & 0.13 \\
\hline Internal strategies & 26.7 & 8.0 & 31 & 29.1 & 4.9 & 29 & .18 & 0.36 \\
\hline RBMT-3 & 90.9 & 12.5 & 31 & 92.3 & 18.3 & 29 & .73 & 0.09 \\
\hline \multicolumn{9}{|l|}{ LLT } \\
\hline Total Displacement score & 28.6 & 23.2 & 31 & 27.2 & 21.3 & 29 & .80 & 0.06 \\
\hline Learning Index & 0.51 & 0.31 & 31 & 0.60 & 0.28 & 29 & .23 & 0.30 \\
\hline Delayed Recall score & -0.35 & 1.9 & 31 & 0.24 & 1.5 & 29 & .18 & 0.34 \\
\hline \multicolumn{9}{|l|}{ RAVLT } \\
\hline Total learning score & 34.7 & 7.9 & 30 & 35.9 & 10.7 & 26 & .65 & 0.13 \\
\hline Recall score & 5.8 & 3.3 & 30 & 6.4 & 3.6 & 26 & .53 & 0.17 \\
\hline Quality of life (RAND-36) & 114.4 & 15.1 & 31 & 111.0 & 19.5 & 29 & .46 & 0.20 \\
\hline \multicolumn{9}{|l|}{ Other neuropsychological tests } \\
\hline Letter Fluency & 34.9 & 10.0 & 30 & 31.7 & 10.1 & 29 & .22 & 0.32 \\
\hline TMT A (sec) & 45.0 & 18.0 & 29 & 48.6 & 18.8 & 25 & .48 & 0.20 \\
\hline TMT B (sec) & 97.5 & 29.0 & 27 & 95.7 & 32.9 & 23 & .84 & 0.06 \\
\hline Digit Span & 23.5 & 5.1 & 31 & 23.9 & 3.9 & 29 & .73 & 0.09 \\
\hline \multicolumn{9}{|l|}{ Self-report measures } \\
\hline GDS-15 & 2.8 & 2.5 & 31 & 2.7 & 2.9 & 27 & .89 & 0.04 \\
\hline IADL & 1.0 & 1.9 & 31 & 1.0 & 1.4 & 29 & .94 & 0.00 \\
\hline
\end{tabular}

Note. ISCED = International Standard Classification of Education; RBMT-3 = Rivermead Behavioural Memory Test - Third Edition; LLT = Location Learning Test - Revised; RAVLT=Rey Auditory Verbal Learning Test; TMT=Trail Making Test; RAND-36=RAND 36-item Short Form Health Survey; GDS-15 = Geriatric Depression Scale; IADL = Instrumental Activities of Daily Living scale.

improvement in the memory strategy training group. In the control memory training group, no significant predictors were found for improvement after treatment.

In addition, we examined whether age, education level, and IQ estimate predicted the increase in internal strategy use (T1-T0), but no significant predictors were found.

\section{DISCUSSION}

Older adults with subjective memory complaints report a larger improvement in personal memory goals, which is a measure of memory functioning in daily life, following memory strategy training compared to a control memory training in an RCT. Although both interventions led to improvement in objective memory functioning and in the personal memory goals, only the improvement on the personal memory goals was found to be significantly larger for the memory strategy training group. Six months after finishing the memory strategy training, $76 \%$ of the participants reported a clinically significant improvement on their personal memory goals, compared to $23 \%$ of the participants who completed the control memory training.

These results are in line with previous studies on the effect of memory training in older adults with subjective memory complaints or MCI (Metternich et al., 2010; Reijnders, van Heugten, \& van Boxtel, 2013). Previous studies have shown that psychoeducation, expectancy management, and sharing experiences in a group are effective elements in memory interventions (Flynn \& Storandt, 1990; Metternich et al., 2010; Reijnders, Geusgens, Ponds, \& van Boxtel, 2017; Valentijn et al., 2005), which could explain why both interventions in our study led to an improvement in memory test performance and in subjective memory functioning in daily life. The additional effect of memory strategy training in the present study seems to be related to the use of memory strategies, as we found that an increase in the use of internal strategies in daily life was positively correlated with the increase in personal goal ratings and to a decrease in subjective memory complaints after memory strategy training. 


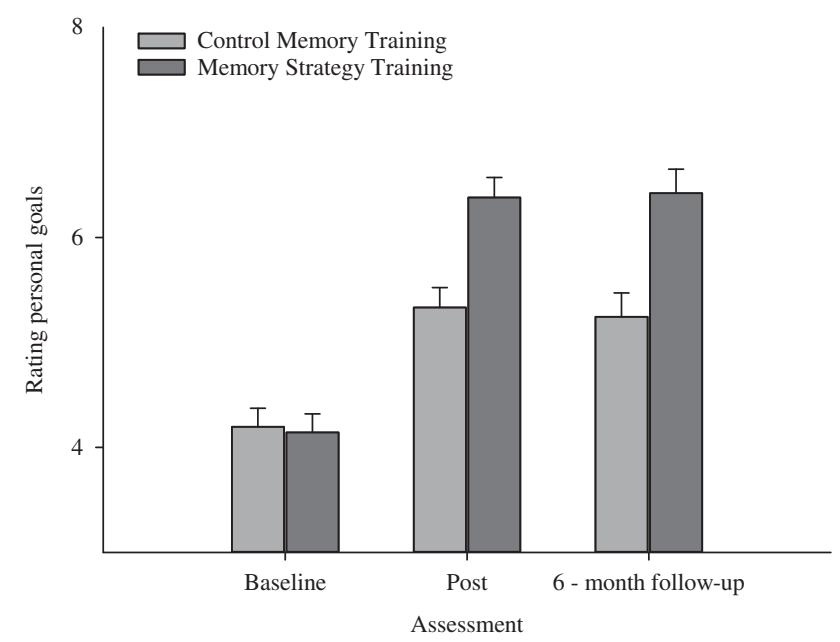

Fig. 2. Average scores of the three personal goal ratings for the memory strategy training group and the control memory training group at baseline (T0), post-training (T1), and 6-month follow-up (T2). There was a significant increase in both groups $(p<.0005)$ and a significant interaction effect $(p=.002)$. Standard error bars are shown.

Both intervention groups showed an improvement on two memory tests: the LLT and RAVLT. Except for the Learning Index of the LLT, memory strategy training did not have an additional effect on memory task performance. Previous studies on memory strategy training have found positive effects on objective cognitive functions (Cavallini, Dunlosky, Bottiroli, Hertzog, \& Vecchi, 2010; Li et al., 2016; Talib, Yassuda, Diniz, Forlenza, \& Gattaz, 2008). However, these studies mainly used laboratory tasks to train the memory strategies and did not examine generalization to daily life.

Since older adults with subjective memory complaints still perform within the normal range on cognitive tasks yet experience their complaints in daily life situations, it could be argued that memory training should be aimed at improving memory functioning in daily life situations. Therefore, the present study included homework assignments to implement strategies in daily life, and did not actively stimulate the use of strategies during memory tests. Since participants did not practice using strategies in test situations and, since we found no interaction effects on any of the performance measures of the memory tests, it is unlikely that the interaction effect on the Learning Index of the LLT is the result of more efficient memory strategy use. Furthermore, the finding that both intervention groups improved on two memory tests could also be the result of test-retest effects. Although we used the available alternate forms for the memory tests, non-specific practice effects cannot be ruled out entirely (Goldberg, Harvey, Wesnes, Snyder, \& Schneider, 2015).

Following memory strategy training, adults used relatively more internal strategies in daily life, whereas the use of external strategies remained unchanged. A possible explanation for this is that older adults tend to use more memory strategies spontaneously to compensate for their experienced memory decline (Frankenmolen, Overdorp, 
Fasotti, Claassen, Kessels, \& Oosterman, 2017). This is especially the case with external strategies, the use of which increases with age (Bouazzaoui et al., 2010). This might indicate that there is little room left for improvement in external strategy use.

However, previous studies suggest that although older adults with SMC use strategies, they often struggle to apply the learned strategies effectively (Frankenmolen, Overdorp, et al., 2017; Pike, Zeneli, Ong, Price, \& Kinsella, 2015). Therefore, memory strategy training was not only aimed at increasing strategy use in daily life, but mainly focused on implementing and using the strategies more effectively in daily life situations. For example, most adults were familiar with making notes of important information, but during the training they learned to organize this written information more efficiently. Although the increase in personal goal ratings gives an indication of the effectiveness of the learned strategies, we did not examine this effect directly. Future studies on memory strategy use should include measures of effectiveness of the applied strategies.

Furthermore, effective implementation of strategies has been related to a higher IQ level (Frankenmolen, Altgassen, et al., 2017; Frankenmolen, Fasotti, Kessels, \& Oosterman, 2018), which may be a proxy for cognitive reserve (Stern, 2009; Galioto, Alosco, Spitznagel, Stanek, \& Gunstad, 2013). Cognitive reserve is suggested to be protective against cognitive decline and to facilitate successful compensation (Stern, 2012). In the present study, IQ estimate did not significantly predict the increase in strategy use or improvement following training. Although we made a first attempt to examine predictors of treatment success following memory strategy training, these analyses were exploratory in nature and were not based on $a$ priori hypotheses. Future studies with larger groups of participants should investigate which participants benefit most from memory strategy training at an individual level and, specifically, whether (proxies of) cognitive reserve increases the beneficial effects of strategy training.

Homework assignments of the memory strategy training were aimed at using strategies in the context of the three personal goals to improve daily life memory functioning. Older adults typically show limited transfer of the learned strategies to untrained situations (Cavallini et al., 2010). In this line, we found that adults improved meaningfully on their personal goals, while showing no significant decrease on the subjective memory complaints questionnaire, which included mostly untrained situations. Since generalization of the learned strategies is limited, it is important to actually train the use of memory strategies in these daily-life situations by including homework assignments.

Although this training setup included three memory goals that are functionally most important to the individual, future studies should examine whether additional sessions aimed at using strategies in other daily life situations increases transfer to untrained situations. For example, generalization could be improved by stimulating participants to reflect on how strategies could be used in other daily life situations and by practicing these situations within the sessions and at home.
The memory strategy training in this study contains a tailored approach in which individually selected memory goals were chosen and rated by the participants, thereby increasing the feasibility of the training for each participant. Although this approach is clinically relevant, a limitation is that the personal goal rating scale is a subjective measure, which needs further validation in future research. Another limitation of this study is that the control memory training did not have homework assignments. Therefore, it is possible that the additional time and attention that was spent on the personal goals contributed to the improvement of personal goal ratings in the memory strategy training group.

Furthermore, since one trainer performed all training sessions to prevent therapist effects (Firth, Barkham, Kellett, \& Saxon, 2015), it was not possible to blind the trainer to treatment condition. As a result, a bias in personal preference of the trainer for the experimental condition cannot be ruled out.

In conclusion, this randomized and controlled study shows that memory strategy training improves memory functioning in daily life situations. The combination of psycho-education, expectancy management, sharing experiences in a group, and training to use memory strategies in daily life situations is effective in older adults with subjective memory complaints and could be implemented in clinical practice.

\section{ACKNOWLEDGMENTS}

We thank the psychology students who performed the assessments and thank the participants and for their contributions to this study. We also thank Radboud University Medical Centre Nijmegen, Canisius-Wilhelmina Hospital Nijmegen and Gelre Hospitals Zutphen for facilitating the inclusion of participants. This study is funded by the NutsOhra Foundation (Grant \#1203-049), awarded to Dr. Oosterman. Conflicts of interest: None declared.

\section{SUPPLEMENTARY MATERIAL}

To view supplementary material for this article, please visit https://doi.org/10.1017/S1355617718000619

\section{REFERENCES}

Altman, D.G., Schulz, K.F., Moher, D., Egger, M., Davidoff, F., Egger, M., ... Lang, T. (2001). The revised CONSORT statement for reporting randomized trials: Explanation and elaboration. Annals of Internal Medicine, 134, 663-694. doi: 10.7326/00034819-1348-200104170-00012

Balash, Y., Mordechovich, M., Shabtai, H., Giladi, N., Gurevich, T., \& Korczyn, A.D. (2013). Subjective memory complaints in elders: Depression, anxiety, or cognitive decline? Acta Neurologica Scandinavica, 127, 344-350. doi: 10.1111/ane.12038

Bouazzaoui, B., Isingrini, M., Fay, S., Angel, L., Vanneste, S., Clarys, D., ... Taconnat, L. (2010). Aging and self-reported internal and external memory strategy uses: The role of executive functioning. Acta Psychologica, 135, 59-66. doi: 10.1016/j. actpsy.2010.05.007 
Brazier, J.E., Harper, R., Jones, N.M., O'Cathain, A., Thomas, K.J., Usherwood, T., ... Westlake, L. (1992). Validating the SF-36 health survey questionnaire: New outcome measure for primary care. British Medical Journal, 305, 160-164. doi: 10.1136/bmj.305.6846.160

Bucks, R.S., Willison, J.R., Byrne, L.M.T., \& Kessels, R.P.C. (2011). Location Learning Test - Revised edition. Amsterdam, the Netherlands: Hogrefe.

Cavallini, E., Dunlosky, J., Bottiroli, S., Hertzog, C., \& Vecchi, T. (2010). Promoting transfer in memory training for older adults. Aging Clinical and Experimental Research, 22, 314-323. doi: $10.3275 / 6704$

Deelman, B.G., \& Saan, R.J. (1990). Memory deficits: Assessment and recovery. In B.G. Deelman, R.J. Saan \& A.H. van Zomeren (Eds.), Traumatic brain injury: Clinical, social and rehabilitation aspects (pp. 49-76). Lisse, The Netherlands: Swets \& Zeitlinger.

Evans, C., Margison, F., \& Barkham, M. (1998). The contribution of reliable and clinically significant change methods to evidencebased mental health. Evidence Based Mental Health, 1, 70-72. doi: 10.1136/ebmh.1.3.70

Firth, N., Barkham, M., Kellett, S., \& Saxon, D. (2015). Therapist effects and moderators of effectiveness and efficiency in psychological wellbeing practitioners: A multilevel modelling analysis. Behaviour Research and Therapy, 69, 54-62. doi: 10.1016/j.brat.2015.04.001

Flynn, T.M., \& Storandt, M. (1990). Supplemental group discussions in memory training for older adults. Pyschology \& Aging, 5, 178-181.

Frankenmolen, N.L., Altgassen, M., Kessels, R., de Waal, M., Hindriksen, J.A., Verhoeven, B., ... Oosterman, J. (2017). Intelligence moderates the benefits of strategy instructions on memory performance: An adult-lifespan examination. Aging, Neuropsychology, and Cognition, 24, 45-61. doi: 10.1080/ 13825585.2016.1171289

Frankenmolen, N.L., Fasotti, L., Kessels, R.P.C., \& Oosterman, J.M. (2018). The influence of cognitive reserve and age on the use of memory strategies. Experimental Aging Research, 44, 117-134. doi: 10.1080/0361073X.2017.1422472

Frankenmolen, N.L., Overdorp, E.J., Fasotti, L., Claassen, J.A.H.R., Kessels, R.P.C., \& Oosterman, J.M. (2017). Memory strategy use in older adults with subjective memory complaints. Aging Clinical and Experimental Research, 29, 1061-1065. doi: 10.1007/s40520-016-0635-1

Galioto, R.M., Alosco, M.L., Spitznagel, M.B., Stanek, K.M., \& Gunstad, J. (2013). Cognitive reserve preserves cognitive function in obese individuals. Aging, Neuropsycholog, and Cognition, 20, 684-699. doi: 10.1080/13825585.2012.762 972

Goldberg, T.E., Harvey, P.D., Wesnes, K.A., Snyder, P.J., \& Schneider, L.S. (2015). Practice effects due to serial cognitive assessment: Implications for preclinical Alzheimer's disease randomized controlled trials. Alzheimers Dementia, 1, 103-111. doi: 10.1016/j.dadm.2014.11.003

Gross, A.L., Parisi, J.M., Spira, A.P., Kueider, A.M., Ko, J.Y., Saczynski, J.S., ... Rebok, G.W. (2012). Memory training interventions for older adults: A meta-analysis. Aging \& Mental Health, 16, 722-734. doi: 10.1080/13607863.2012.667783

Gupta, S.K. (2011). Intention-to-treat concept: A review. Perspectives in Clinical Research, 2, 109-112. doi: 10.4103/22293485.83221
Jacobson, N.S., \& Truax, P. (1991). Clinical significance: A statistical approach to defining meaningful change in psychotherapy research. Journal of Consulting and Clinical Psychology, 59, 12-19. doi: 10.1037/0022-006X.59.1.12

Jessen, F., Amariglio, R.E., van Boxtel, M., Breteler, M., Ceccaldi, M., Chételat, G., ... Wagner, M. (2014). A conceptual framework for research on subjective cognitive decline in preclinical Alzheimer's disease. Alzheimer's \& Dementia, 10, 844-852. doi: 10.1016/j.jalz.2014.01.001

Kempen, G.I.J.M., Meier, A.J.L., Bouwens, S.F.M., van Deursen, J., \& Verhey, F.R.J. (2007). Telefonisch Interview Cognitieve Status (TICS): Psychometrische aspecten. [Telephone Interview Cognitive Status: Psychometric properties]. Tijdschrift voor Gerontologie en Geriatrie, 38, 34-40. doi: 10.1007/BF03074823

Koning-Haanstra, M., Berg, I.J., \& Deelman, B.G. (1990). Training memory strategies: Description of a method. In B.G. Deelman, R.J. Saan \& A.H. van Zomeren (Eds.), Traumatic brain injury: Clinical, social and rehabilitation aspects (pp. 145-168). Lisse, The Netherlands: Swets \& Zeitlinger.

Lachman, M.E., Weaver, S.L., Bandura, M., Elliott, E., \& Lewkowicz, C.J. (1992). Improving memory and control beliefs through cognitive restructuring and self-generated strategies. Journal of Gerontology, 27, 293-299.

Lawton, M.P., \& Brody, E.M. (1969). Assessment of older people: Self maintaining and instrumental activities of daily living. Gerontologist, 9, 179-186.

Lezak, M.D., Howieson, D., Bigler, E., \& Tranel, D. (2012). Neuropsychological assessment (5th ed.). New York: Oxford University Press.

Li, B., Zhu, X., Hou, J., Chen, T., Wang, P., \& Li, J. (2016). Combined cognitive training vs. Memory strategy training in healthy older adults. Frontiers in Psychology, 7, doi: 10.3389/ fpsyg.2016.00834

Luck, T., Luppa, M., Matschinger, H., Jessen, F., Angermeyer, M.C., \& Riedel-Heller, S.G. (2015). Incident subjective memory complaints and the risk of subsequent dementia. Acta Psychiatrica Scandinavia, 131, 290-296. doi: 10.1111/acps.12328

Mendonça, M.D., Alves, L., \& Bugalho, P. (2016). From subjective cognitive complaints to dementia: Who is at risk? A systematic review. American Journal of Alzheimer's Disease \& Other Dementias, 31, 105-114. doi: 10.1177/1533317515592331

Metternich, B., Kosch, D., Kriston, L., Härter, M., \& Hüll, M. (2010). The effects of nonpharmacological interventions on subjective memory complaints: A systematic review and metaanalysis. Psychotherapy and Psychosomatics, 79, 6-19. doi: 10.1159/000254901

Mitchell, A.J., Beaumont, H., Ferguson, D., Yadegarfar, M., \& Stubbs, B. (2014). Risk of dementia and mild cognitive impairment in older people with subjective memory complaints: Meta-analysis. Acta Psychiatrica Scandivica, 130, 439-451. doi: 10.1111/acps. 12336

Montejo, P., Montenegro, M., Fernandez, M.A., \& Maestu, F. (2011). Subjective memory complaints in the elderly: Prevalence and influence of temporal orientation, depression and quality of life in a population-based study in the city of Madrid. Aging \& Mental Health, 15, 85-96. doi: 10.1080/13607863.2010.501062

Nasreddine, Z.S., Philips, N.A., Bédirian, V., Charbonneau, S., Whitehead, V., Collin, I., ... Chertkow, H. (2005). The Montreal Cognitive Assessment, MoCA: A brief screening tool for mild cognitive impairment. Journal of the American Geriatrics Society, 53, 695-699. doi: 10.1111/j.1532-5415.2005.53221.x 
Nelson, H.E. (1982). National Adult Reading Test (NART): Test manual. Windsor, UK: NFER-Nelson.

Owen, A.M., Hampshire, A., Grahn, J.A., Stenton, R., Dajani, S., Burns, A.S., ... Ballard, C.G. (2010). Putting brain training to the test. Nature, 465, 775-778. doi: 10.1038/nature09042

Pike, K.E., Zeneli, A., Ong, B., Price, S., \& Kinsella, G.J. (2015). Reduced benefit of memory elaboration in older adults with subjective memory decline. Journal of Alzheimer's Disease, 47, 705-713. doi: 10.3233/JAD-1500

Reijnders, J.S., Geusgens, C.A., Ponds, R.W., \& van Boxtel, M.P. (2017). "Keep your brain fit!" Effectiveness of a psychoeducational intervention on cognitive functioning in healthy adults: A randomized controlled trial. Neuropsychological Rehabilitaton, 27, 455-471. doi: 10.1080/09602011.2015.1090458

Reijnders, J., van Heugten, C., \& van Boxtel, M. (2013). Cognitive interventions in healthy older adults and people with mild cognitive impairment: A systematic review. Aging Research Reviews, 12, 263-275. doi: 10.1016/j.arr.2012.07.003

Schmand, B., Groenink, S.C., \& Van den Dungen, M. (2008). Letterfluency: Psychometrische eigenschappen en Nederlandse normen [Letter fluency: Psychometric properties and Dutch normative data]. Tijdschrift voor Gerontologie en Geriatrie, 39, 64-76.

Scogin, F., \& Prohaska, M. (1992). The efficacy of self-taught memory training for community-dwelling older adults. Educational Gerontology, 18, 751-766. doi: 10.1080/0360127920180801

Sheikh, J.I., \& Yesavage, Y.A. (1986). Geriatric Depression Scale (GDS): Recent evidence and development of a shorter version. In T.L. Brink (Ed.), Clinical gerontology: A guide to assessment and intervention (pp. 165-173). New York, NY: Haworth Press.

Stern, Y. (2009). Cognitive reserve. Neuropsychologia, 47, 2015-2028. doi: 10.1016/j.neuropsychologia.2009.03.004
Stern, Y. (2012). Cognitive reserve in ageing and Alzheimer's disease. Lancet Neurology, 11, 1006-1012. doi: 10.1016/S14744422(12)70191-6

Talib, L.L., Yassuda, M.S., Diniz, B.S.O., Forlenza, O.V., \& Gattaz, W.F. (2008). Cognitive training increases platelet PLA $_{2}$ activity in healthy elderly subjects. Postaglandins, Leukotrienes \& Essential Fatty Acids, 78, 265-269. doi: 10.1016/j.plefa.2008.03.002

Turner-Stokes, L. (2009). Goal attainment scaling (GAS) in rehabilitation: A practical guide. Clinical Rehabilitation, 23, 362-370. doi: 10.1177/0269215508101742

Valentijn, S.A.M., van Hooren, S.A.H., Bosma, H., Touw, D.M., Jolles, J., van Boxtel, M.P.J., ... Ponds, R.W.H.M. (2005). The effect of two types of memory training on subjective and objective memory performance in healthy individuals aged 55 years and older: A randomized controlled trial. Patient Education and Counseling, 57, 106-114. doi: 10.1016/j.pec.2004.05.002

Van der Elst, W., van Boxtel, M., van Breukelen, G.J.P., \& Jolles, J. (2005). Rey's verbal learning test: Normative data for 1855 healthy participants aged 24-81 years and the influence of age, sex, education, and mode of presentation. Journal of the International Neuropsychological Society, 11, 290-302. doi: 10.1017/S1355617705050344

Van Heugten, C.M., Ponds, R.W.H.M., \& Kessels, R.P.C. (2016). Brain training: Hype or hope? Neuropsychological Rehabilitation, 26, 639-644. doi: 10.1080/09602011.2016.1186101

Wechsler, D. (2008). Wechsler Adult Intelligence Scale - Fourth Edition (WAIS-IV). San Antonio, TX: The Psychological Corporation.

Wilson, B.A., Greenfeld, E., Clare, L., Baddely, A., Cockburn, J., Watson, P., ... Nannery, R. (2008). Rivermead Behavioural Memory Test (3rd ed.). Toronto: Pearson. 